Gynecologic and

Obstetric Investigation
Received: September 23, 2009

Accepted after revision: May 31, 2010

Published online: December 14, 2010

\title{
Vaginal Flora Alterations and Clinical Symptoms in Low-Risk Pregnant Women
}

\author{
Fausto Gondo ${ }^{a}$ Márcia G. da Silva ${ }^{b}$ Jossimara Polettini ${ }^{b} \quad$ Andréa da R. Tristao $^{a}$ \\ José C. Peracoli ${ }^{a}$ Steven S. Witkin ${ }^{c}$ Marilza V.C. Rudge ${ }^{a}$ \\ Departments of a Gynecology and Obstetrics and ${ }^{b}$ Pathology, Botucatu Medical School, UNESP - São Paulo \\ State University, Botucatu, Brazil; ' ${ }^{C}$ Department of Obstetrics and Gynecology, Weill Medical College of \\ Cornell University, New York, N.Y., USA
}

\section{Key Words \\ Vaginal flora $\cdot$ Bacterial vaginosis $\cdot$ Candidosis $\cdot$ Aerobic vaginitis $\cdot$ Vaginal symptoms $\cdot$ Pregnancy}

\begin{abstract}
Background: To evaluate associations between alterations in vaginal flora and clinical symptoms in low-risk pregnant women. Methods: Vaginal specimens from 245 pregnant women were analyzed by microscopy for vaginal flora. Signs and symptoms of vaginal infection were determined by patient interviews and gynecologic examinations. Results: Abnormal vaginal flora was identified in $45.7 \%$ of the subjects. The final clinical diagnoses were bacterial vaginosis (21.6\%), vaginal candidosis (10.2\%), intermediate vaginal flora (5.2\%), aerobic vaginitis (2.9\%), mixed flora (2.9\%) and other abnormal findings (2.9\%). The percentage of women with or without clinical signs or symptoms was not significantly different between these categories. The presence of vaginal odor or vaginal discharge characteristics was not diagnostic of any specific flora alteration; pruritus was highly associated with candidosis ( $p<0.0001$ ). Compared to women with normal flora, pruritus was more prevalent in women with candidosis ( $p<0.0001)$, while vaginal odor was associated with bacte-
\end{abstract}

(C) 2010 S. Karger AG, Basel

$0378-7346 / 11 / 0713-0158 \$ 38.00 / 0$

Fax +41613061234

E-Mail karger@karger.ch

www.karger.com
Accessible online at: www.karger.com/goi rial vaginosis $(p=0.0026)$. Conclusion: The prevalence of atypical vaginal flora is common in our low-risk pregnant population and is not always associated with pathology. The occurrence of specific signs or symptoms does not always discriminate between women with different types of atypical vaginal flora or between those with abnormal and normal vaginal flora.

Copyright $\odot 2010$ S. Karger AG, Basel

\section{Introduction}

Recent studies utilizing noncultivation gene amplification methodologies have challenged long-held assumptions that the microbial flora of the vagina of women of reproductive age is always dominated by lactobacilli [1]. Not only are there large differences in the vaginal bacterial composition between healthy asymptomatic women, but ethnic differences in the composition of the flora are also evident [2]. Furthermore, there is evidence that the composition of the vaginal flora is not static in many women but varies from cycle to cycle $[3,4]$.

Another area of controversy is in determining associations between vaginal flora differences and specific 
clinical symptoms. A good example is the condition known as bacterial vaginosis (BV). BV is defined as an alteration in vaginal flora resulting in a large decrease in or total loss of lactobacilli, accompanied by a massive increase in the concentration of anaerobic and facultatively anaerobic bacteria [5]. However, many women with BV are asymptomatic and remain so over long periods of time [6]. Due to differences in the development of signs or symptoms among individual women, several studies have concluded that clinical criteria cannot accurately predict specific vaginal flora alterations [7-9].

An important issue is whether or not to treat women based on the composition of their vaginal flora, regardless of the presence or absence of clinical symptoms. Several studies have concluded that BV is associated with increased susceptibility to preterm birth as well as other pregnancy complications $[10,11]$. However, due to the lack of efficacy in some studies to reduce the preterm birth rate by treating women with BV, the current recommendation is not to screen for this vaginal flora alteration, at least in those pregnant women who do not have additional risk factors for a premature delivery [12].

The present study was undertaken to establish the prevalence of vaginal flora alterations in low-risk pregnant women attending the Family Health Strategy of the Primary Care Services in Botucatu, São Paulo state, Brazil. Furthermore, we sought to evaluate whether specific vaginal flora alterations were associated with defined symptoms.

\section{Subjects and Methods}

\section{Subjects}

The study was conducted at 8 Family Health Strategy units of the Primary Care Services in Botucatu, Brazil (Brazilian Unified Healthcare System, Sistema Único de Saúde). These clinics serve the majority of inhabitants of the city. The pregnant population at each service was one of convenience with no attempt to select participants based on any specific criteria. Botucatu is a city of 130,000 people, located in the middle of São Paulo state. The population is of low income and reflects the ethnic distribution of the country. The institution's research and ethical committee of the Botucatu Medical School, UNESP - São Paulo State University, approved the study, and all women gave written informed consent. Pregnant women between 5 and 40 weeks of gestation receiving routine antenatal care at the study sites were screened for eligibility from September 2006 to February 2007. A total of 245 pregnant women were enrolled. The sample size was calculated considering the CI of $95 \%$, a precision of $5 \%$ and a general prevalence of vaginal flora alterations estimated at $20 \%$. A standardized medical, obstetric, sexual and social history was obtained from each subject. Subjects were excluded from the study for the following reasons: vaginal bleeding; current antibiotics use or vaginal medication in the 30 days prior to sample collection, or sexual intercourse or a vaginal procedure in the $72 \mathrm{~h}$ preceding the examination. Ethnicity was self-reported.

\section{Specimen Collection}

A clean, unlubricated speculum was placed into the vagina, and the appearance and type of vaginal secretions were recorded. Sterile cotton swabs were used to obtain material from the upper lateral vaginal vault for determination of vaginal $\mathrm{pH}$, preparation of Gram-stained slides, direct microscopic examination of vaginal contents and detection of an amine odor after exposure of vaginal secretions to $10 \% \mathrm{KOH}$. The protocol was standardized for all 8 Family Health Strategy units.

\section{Signs and Symptoms}

The characteristics of the vaginal discharge, presence of a vaginal odor, vaginal pruritus or genital burning, as defined by the individual women and their caregivers, were considered as signs and symptoms. There was an overwhelming consensus between patient and clinician on these parameters.

\section{Diagnoses}

The diagnosis of vaginal candidosis was based on the presence of yeast blastospores or pseudohyphae in wet mounts [13]. BV and intermediate vaginal flora were diagnosed by Gram stain using the criteria by Nugent et al. [14] and aerobic vaginitis was diagnosed if vaginal smears were deficient in lactobacilli, positive for cocci or coarse bacilli, positive for parabasal epithelial cells and/ or positive for vaginal leucocytes [15]. Mixed infections were defined as those positive for both BV and vaginal candidosis. The presence of leukocytes on a Gram stain in the absence of trichomonads, candidosis, leptothrix or characteristics of aerobic vaginitis received a designation of 'other abnormal flora'. Altered vaginal flora was defined either as flora in which lactobacilli did not predominate (e.g. BV, intermediate flora, aerobic vaginitis) or flora positive for Candida species by microscopy. All stained slides were read by experienced observers at the Botucatu Medical School, who were blinded to the clinical data. The possible presence of Trichomonas vaginalis was evaluated by wet mount microscopy; all samples were negative. All subjects were routinely tested and were negative for Chlamydia trachomatis and Neisseria gonorrhoeae by standard culture and antigen detection techniques.

Since the study participants were from 8 different sites and delivered at various locations, pregnancy outcome data were not available.

\section{Statistics}

The data were analyzed via descriptive tables of the variables studied, establishing the prevalence of the types of flora, and were entered into a database and analyzed by SPSS (version 12.0; SPSS Inc., Chicago, Ill., USA) and R (version 2.4.1; R Development Core Team) statistical software. Fisher's exact test and the $\chi^{2}$ test were used to analyze classified data, and the Mann-Whitney test to numeric data. Odds ratios (OR) and 95\% CI were also determined. $\mathrm{p}<0.05$ was considered significant. 
Table 1. Characteristics of the study population

\begin{tabular}{|c|c|c|c|c|c|c|c|}
\hline & \multirow[t]{2}{*}{$\mathrm{n}$} & \multirow[t]{2}{*}{$\%$} & \multicolumn{2}{|c|}{$\begin{array}{l}\text { Women } \\
\text { without } \\
\text { altered flora }\end{array}$} & \multicolumn{2}{|c|}{$\begin{array}{l}\text { Women } \\
\text { with altered } \\
\text { flora }\end{array}$} & \multirow[t]{2}{*}{$\mathrm{p}$} \\
\hline & & & $\mathrm{n}$ & $\%$ & $\mathrm{n}$ & $\%$ & \\
\hline \multicolumn{8}{|l|}{ Age, years } \\
\hline Median & & & \multicolumn{2}{|c|}{25.7} & \multicolumn{2}{|c|}{23.8} & $0.060^{1}$ \\
\hline Range & & & \multicolumn{2}{|c|}{$15-44$} & \multicolumn{2}{|c|}{$14-44$} & \\
\hline \multicolumn{8}{|l|}{ Ethnicity } \\
\hline White & 199 & 81.2 & 98 & 80.3 & 101 & 82.1 & $0.846^{2}$ \\
\hline Black & 11 & 4.5 & 4 & 3.3 & 7 & 5.7 & $0.546^{2}$ \\
\hline Other & 35 & 14.3 & 20 & 16.4 & 15 & 12.2 & $0.449^{2}$ \\
\hline \multicolumn{8}{|l|}{ Marital status } \\
\hline Single & 92 & 38.0 & 41 & 33.1 & 52 & 43.0 & $0.142^{2}$ \\
\hline Married & 139 & 57.1 & 78 & 62.9 & 62 & 51.2 & $0.086^{2}$ \\
\hline Other & 11 & 4.9 & 5 & 4.0 & 7 & 5.8 & $0.734^{2}$ \\
\hline \multicolumn{8}{|l|}{ Education } \\
\hline$<8$ years & 177 & 72.2 & 89 & 71.2 & 88 & 73.3 & $0.818^{2}$ \\
\hline$\geq 8$ years & 68 & 27.8 & 36 & 28.8 & 32 & 26.7 & $0.818^{2}$ \\
\hline \multicolumn{8}{|l|}{ Parity } \\
\hline Nulliparous & 77 & 31.4 & 32 & 28.6 & 45 & 36.6 & $0.242^{2}$ \\
\hline Multiparous & 168 & 68.6 & 90 & 71.4 & 78 & 63.4 & $0.242^{2}$ \\
\hline Abortion & 45 & 18.4 & 26 & 74.3 & 9 & 25.7 & \\
\hline \multicolumn{8}{|l|}{ Trimester } \\
\hline First & 78 & 32.1 & 38 & 31.4 & 40 & 32.8 & $0.925^{2}$ \\
\hline Second & 97 & 39.9 & 48 & 39.6 & 49 & 40.2 & $1.000^{2}$ \\
\hline Third & 68 & 28.0 & 35 & 28.9 & 33 & 27.0 & $0.859^{2}$ \\
\hline
\end{tabular}

\section{Results}

In the study population, $45.7 \%$ of the women fit our definition of having abnormal vaginal flora. The relationship between vaginal flora designation and demographic characteristics is shown in table 1 . There were no significant differences in age, ethnicity, marital status, education, parity or time of sample collection between women with normal or abnormal flora.

The specific clinical diagnosis based on the characterization of the vaginal flora is shown in table 2. BV was diagnosed in $21.6 \%$ of the women, vaginal candidosis was present in $10.2 \%, 5.2 \%$ possessed intermediate vaginal flora and $2.9 \%$ had flora consistent with a diagnosis of aerobic vaginitis.

The relationship between clinical diagnosis and the presence or absence of symptoms is shown in table 2. Interestingly, more than half of the women with normal
Table 2. Association between clinical diagnosis and the presence or absence of clinical signs or symptoms

\begin{tabular}{|c|c|c|c|c|c|c|}
\hline & \multicolumn{2}{|c|}{$\begin{array}{l}\text { Signs or } \\
\text { symptoms }\end{array}$} & \multicolumn{2}{|c|}{$\begin{array}{l}\text { Asymp- } \\
\text { tomatic }\end{array}$} & \multicolumn{2}{|c|}{ Total } \\
\hline & $\mathrm{n}$ & $\%$ & $\mathrm{n}$ & $\%$ & $\mathrm{n}$ & $\%$ \\
\hline $\mathrm{BV}$ & 35 & 66.0 & 18 & 34.0 & 53 & 21.6 \\
\hline Vaginal candidosis & 23 & $92.0^{\mathrm{a}}$ & 2 & 8.0 & 25 & 10.2 \\
\hline Intermediate flora & 9 & 69.2 & 4 & 30.8 & 13 & 5.2 \\
\hline Aerobic vaginitis & 3 & 42.9 & 4 & 57.1 & 7 & 2.9 \\
\hline Mixed infection & 6 & 85.7 & 1 & 14.3 & 7 & 2.9 \\
\hline Other abnormal flora & 5 & 71.4 & 2 & 28.6 & 7 & 2.9 \\
\hline Normal flora & 76 & 57.1 & 57 & 42.9 & 133 & 54.3 \\
\hline
\end{tabular}

${ }^{\mathrm{a}} \mathrm{p}=0.0006$ versus normal flora (OR: 8.625; 95\% CI: 1.953 , 38.099).

Table 3. Association between symptoms and specific alterations in vaginal flora (\%)

\begin{tabular}{llllll}
\hline & $\begin{array}{l}\text { Normal } \\
\text { flora } \\
(\mathrm{n}=133)\end{array}$ & $\begin{array}{l}\text { BV } \\
(\mathrm{n}=53)\end{array}$ & $\begin{array}{l}\text { Candidosis } \\
(\mathrm{n}=25)\end{array}$ & $\begin{array}{l}\text { Aerobic } \\
\text { vaginitis } \\
(\mathrm{n}=7)\end{array}$ & $\begin{array}{l}\text { Intermediate } \\
\text { flora } \\
(\mathrm{n}=13)\end{array}$ \\
\hline $\begin{array}{l}\text { Pruritus } \\
\text { Odor }\end{array}$ & 12.8 & 18.9 & $72.0^{\mathrm{a}, \mathrm{b}}$ & 14.3 & 7.7 \\
$\begin{array}{l}\text { Discharge } \\
\quad \text { Thin }\end{array}$ & 15.0 & $35.8^{\mathrm{c}}$ & 28.0 & 0 & 7.7 \\
$\quad$ & 39.1 & 54.7 & 20.0 & 14.3 & 61.5 \\
$\quad \begin{array}{l}\text { Thick } \\
\text { White }\end{array}$ & 21.8 & 20.8 & 40.0 & 28.6 & 23.1 \\
$\quad$ Nonwhite & 153.4 & 50.0 & 59.1 & 57.1 & 61.5 \\
\hline
\end{tabular}

${ }^{\mathrm{a}} \mathrm{p}<0.0001$ versus normal flora (OR: 17.546; 95\% CI: 6.385, 48.215); ${ }^{b} \mathrm{p}<0.0001$ versus BV (OR: 11.057; 95\% CI: 3.637, 33.613); ${ }^{c} \mathrm{p}=0.0026$ versus normal flora (OR: 3.157 ; 95\% CI: $1.513,6.590$ ).

vaginal flora were positive for vaginal symptoms (57.1\%). Except for women with vaginal candidosis, this percentage was similar to the percentage of women with abnormal vaginal flora who also had symptoms. Among women with candidosis, $92.0 \%$ were symptomatic $(\mathrm{p}=0.0006$ vs. normal flora).

The association between specific signs and symptoms and vaginal flora characteristics is shown in table 3 . Pruritus was highly associated with a diagnosis of vaginal candidosis ( $\mathrm{p}<0.0001$ vs. normal flora or BV flora). A vaginal odor was more prevalent in women with $\mathrm{BV}$ than in those with normal flora $(\mathrm{p}=0.0026)$; however, its occurrence was not significantly different from that in women with vaginal candidosis $(\mathrm{p}=0.609)$. The specific 
characteristics of the odor were not recorded. The presence, consistency or color of a vaginal discharge did not significantly differ between groups or between women with normal or abnormal flora.

\section{Discussion}

Among our low-risk pregnant population in a small rural city in Brazil, almost half of the 245 women tested had a vaginal flora that would be considered abnormal by current standards. The most prevalent type of abnormal flora was consistent with a clinical diagnosis of BV followed by flora characteristic of vaginal candidosis. While there were small quantitative variations in some cases between specific types of flora or clinical diagnosis and individual symptoms, it was apparent that the appearance of specific symptoms varied among women with the same flora pattern as well as between women with normal and abnormal flora. The prevalence of $45.7 \%$ of altered vaginal flora observed in this population of pregnant women attending the Family Health Strategy of the Primary Care Services was similar to that observed in another Brazilian pregnancy study [16]. BV was the most prevalent infection in our study, being present in $21.6 \%$ of the pregnant women. The BV detection rate has been reported to vary from 9 to $28 \%$ [17]. A recent study in the USA identified BV in $16.2 \%$ of 13,357 pregnant women [18], a frequency similar to that present in our population. The occurrence of intermediate vaginal flora in our study (5.2\%) was similar to that described previously for Brazilian women [16]. The percentage of women in our study with normal vaginal flora who were identified as being positive for clinical signs or symptoms (57.1\%) did not differ from that of symptomatic women with BV (66.0\%), intermediate flora (69.2\%) or aerobic vaginitis (42.9\%). This suggests that a high percentage of healthy pregnant women have vaginal characteristics that can be misclassified as abnormal. Thus, we conclude that in this population, vaginal flora disparities and the presence or absence of vaginal symptoms are most likely normal variations and probably not pathological. Further studies utilizing more sophisticated gene amplification techniques are necessary to completely rule out the presence of low levels of T. vaginalis or other potential pathogens that may have led to an erroneous classification of some subjects.

Other factors undoubtedly influence whether or not specific alterations in the vaginal ecosystem will result in adverse consequences. Individual discrepancies in the extent and direction of the host's immune response to specific microorganisms, due to genetic variations, will determine to a large extent the consequences of microbial alterations in the vagina $[19,20]$. Similarly, BV may pose a problem during pregnancy for only a subgroup of women with altered immune characteristics $[21,22]$.

The percentage of women with altered vaginal flora did not differ by ethnicity, marital status, education, parity or trimester in which the sample was collected. While the majority of women self-classified as White, the ancestry of people in Brazil is known to be very heterogeneous. This, along with the low number of non-Whites, may explain the observed lack of ethnic variation in percentages of women with abnormal flora. The lack of heterogeneity with other variables suggests that the vaginal flora characteristics of the study population are relatively constant among all women in this region.

We are certainly aware that screening and treating for BV in unselected populations have been shown in some studies to effectively reduce the rate of preterm birth [23]. In our study, the total number of subjects with BV or with any other specific clinical diagnosis was low, and we have no data on pregnancy outcomes; thus, the debate over whether all pregnant women, regardless of the presence or absence of specific symptoms, should be screened and treated for BV remains unclarified. However, the present study adds to this debate by demonstrating that variations in vaginal flora consistent with a clinical diagnosis of $\mathrm{BV}$, intermediate vaginal flora or vaginal candidosis may occur frequently in low-risk pregnant women and are consistent with nonpathological normal flora variations.

References

1 Zhou X, Bent SJ, Schneider MG, et al: Characterization of vaginal microbial communities in adult healthy women using cultivation-independent methods. Microbiol 2004; 150:2565-2573.

-2 Zhou X, Brown CJ, Abdo Z, et al: Differences in the composition of vaginal microbial communities found in healthy Caucasian and black women. ISME J 2007;1:121-133.

-3 Priestley CJF, Jones BM, Dhar J, et al: What is normal vaginal flora? Genitourin Med 1997;73:23-28.

4 Schwebke JR, Richey CM, Weiss HL: Correlation of behaviors with microbiological changes in vaginal flora. J Infect Dis 1999; 180:1632-1636

$\checkmark 5$ Spiegel CA, Amsel R, Eschenbach D, et al: Anaerobic bacteria in non-specific vaginitis. N Engl J Med 1980;303:601-607. 
-6 Schwebke JR, Desmond R: Natural history of asymptomatic bacterial vaginosis in a highrisk group of women. Sex Transm Dis 2007; 34:876-877.

7 Linhares IM, Witkin SS, Miranda SD, et al: Differentiation between women with vulvovaginal symptoms who are positive or negative for Candida species by culture. Infect Dis Obstet Gynecol 2001;9:221-225.

8 Landers DV, Weisenfeld HC, Heine RP, et al: Predictive value of the clinical diagnosis of lower genital tract infection in women. Am J Obstet Gynecol 2004;190:1004-1010.

$\checkmark 9$ Schwiertz A, Taras D, Rusch K, et al: Throwing the dice for the diagnosis of vaginal complaints? Ann Clin Microbiol Antimicrob 2006;5:4-10.

10 Meis PJ, Goldenberg RL, Mercer B, et al: The preterm prediction study: significance of vaginal infections. National Institute of Child Health and Human Development Maternal-Fetal Medicine Units Network. Am J Obstet Gynecol 1995;173:1231-1235.

-11 Hillier SL, Nugent RP, Eschenbach DA, et al: Association between bacterial vaginosis and preterm delivery of a low-birth-weight infant. N Engl J Med 1995;333;1737-1742.
12 US Preventive Services Task Force: Screening for bacterial vaginosis in pregnancy to prevent preterm delivery: US Preventive Services Task Force recommendation statement. Ann Intern Med 2008;148:214-219.

13 Sobel JD, Faro S, Force RW, et al: Vulvovaginal candidiasis: epidemiologic, diagnostic and therapeutic considerations. Am J Obstet Gynecol 1998;178:203-211.

14 Nugent RP, Krohn MA, Hillier SL: Reliability of diagnosing bacterial vaginosis is improved by a standardized method of Gram stain interpretation. J Clin Microbiol 1991; 29:297-301.

15 Donders GG, Vereecken A, Bosmans E, Dekeersmaecker A, Salembier G, Spitz B: Definition of a type of abnormal vaginal flora that is distinct from bacterial vaginosis: aerobic vaginitis. BJOG 2002;109:34-43.

16 Simões JA, Giraldo PC, Faúndes A: Prevalence of cervicovaginal infections during gestation and accuracy of clinical diagnosis. Infect Dis Obstet Gynecol 1998;6:129-133.

17 Tolosa JE, Chaithongwongwatthana S, Daly $S$, et al: The International Infections in Pregnancy (IIP) study: variations in the prevalence of bacterial vaginosis and distribution of morphotypes in vaginal smears among pregnant women. Am J Obstet Gynecol 2006;195:1198-1204.
18 Carey JC, Klebanoff MA: Is a change in the vaginal flora associated with an increased risk of preterm birth? Am J Obstet Gynecol 2005; 192:1341-1347.

19 Witkin SS, Linhares IM, Giraldo P, Jeremias J, Ledger WJ: Individual immunity and susceptibility to female genital tract infection. Am J Obstet Gynecol 2000;183:252-256.

20 Witkin SS, Linhares IM, Giraldo P: Bacterial flora of the female genital tract: function and immune regulation. Best Pract Res Clin Obstet Gynaecol 2007;21:347-354.

21 Cauci S, McGregor J, Thorsen P, Grove J, Guaschino S: Combination of vaginal $\mathrm{pH}$ with vaginal sialidase and prolidase activities for prediction of low birth weight and preterm birth. Am J Obstet Gynecol 2005; 192:489-496.

22 Witkin SS, Linhares IM, Giraldo P, Ledger WJ: An altered immunity hypothesis for the development of symptomatic bacterial vaginosis. Clin Infect Dis 2007;44:554-557.

23 Varma R, Gupta JK, James DK, Kilby MD: Do screening-preventative interventions in asymptomatic pregnancies reduce the risk of preterm delivery: a critical appraisal of the literature. Eur J Obstet Gynecol Reprod Biol 2006;127:145-159. 